\title{
Inovações institucionais participativas: uma abordagem exploratória da produção brasileira em Administração Pública na RAP e no EnAPG (1990-2014)
}

\author{
ana paula paes de Paula \\ Universidade Federal de Minas Gerais / Faculdade de Ciências Econômicas, Belo Horizonte - MG, Brasil
}

TÂNIA MARGarete MEZZOMO KeINERT

INSTITUTO DE SAÚDE DE SÃo PAULO, SÃo PAULO - SP, BRASIL

\begin{abstract}
Resumo
O objetivo deste artigo é fazer um levantamento exploratório da literatura brasileira sobre Administração Pública, para verificar as investigações conduzidas pela comunidade de pesquisadores sobre as inovações institucionais de caráter participativo, tendo em vista traçar um panorama dos limites e avanços dessas pesquisas, apontando lacunas e estabelecendo uma agenda de investigação. Para isso, discutimos as mudanças nas relações Estado e sociedade e as inovações institucionais de caráter participativo. Em seguida, abordamos a metodologia da pesquisa, que consistiu em uma pesquisa de caráter qualitativo e quantitativo, a fim de selecionar e classificar artigos sobre inovações institucionais participativas, na Revista de Administração Pública (RAP), no período de 1990 a 2014, e nas edições de 2004, 2006, 2008, 2010, 2012 e 2014 do Encontro de Administração Pública e Governança da Associação Nacional de Pós-Graduação em Administração (EnAPG). Para analisar os dados e discutir os resultados, recorremos às distribuições de frequência absoluta e relativa, dispostas em tabelas e gráficos. Na conclusão, apresentamos o status das pesquisas sobre inovações institucionais participativas na área, bem como uma agenda de pesquisa para orientar futuras investigações sobre o tema.
\end{abstract}

Palavras-chave: Participação social. Inovação institucional. Gestão pública.

\section{Participatory institutional innovations: an exploratory approach to the Brazilian literature on Public Administration in RAP and EnAPG (1990-2014)}

\begin{abstract}
This article aims to conduct an exploratory survey of the Brazilian literature on Public Administration, to verify the investigations carried out by the community of scholars addressing institutional innovations with a participatory nature, in order to outline an overview of the limitations and advances of these studies, pointing out gaps and establishing a research agenda. To do this, we discuss the changes in relationships between State and society and the institutional innovations with a participatory nature. Then, we approach the research methodology, which consisted in a research that has a qualitative and quantitative design, in order to select and classify articles on participatory institutional innovations, in Revista de Administração Pública (RAP), within the period from 1990 to 2014, and in the 2004, 2006, 2008, 2010, 2012, and 2014 editions of the Encontro de Administração Pública e Governança da Associação Nacional de Pós-Graduação em Administração (EnAPG). To analyze data and discuss the results, we resorted to absolute and relative frequency distributions, displayed in tables and graphs. In the conclusion, we present the status of studies on participatory institutional innovations in the field, as well as a research agenda to guide further investigations on the theme.
\end{abstract}

Keywords: Social participation. Institutional innovation. Public management.

\section{Innovaciones institucionales participativas: un enfoque exploratorio de la producción brasileña en Administración Pública en la RAP y EnAPG (1990-2014)}

\section{Resumen}

El propósito de este artículo es hacer una encuesta exploratoria de la literatura brasileña en la Administración Pública, para verificar las investigaciones efectuadas por la comunidad de investigación sobre las innovaciones institucionales de carácter participativo, con el fin de dar una visión general de los límites y los avances de estos estudios, señalando las deficiencias y establecer una agenda de investigación. Para ello, se discuten los cambios en las relaciones del Estado y de la sociedad y las innovaciones institucionales de carácter participativo. A continuación se discute la metodología de la investigación, que consistió en una investigación cualitativa y cuantitativa con el fin de seleccionar y ordenar los artículos sobre innovaciones institucionales participativos en la Revista de Administração Pública (RAP), de 1990 a 2014 , y de la ediciones de 2004, 2006, 2008, 2010, 2012 y 2014 del Encontro de Administração Pública e Governança da Associação Nacional de Pós-Graduação em Administração (EnAPG). Para analizar los datos y los resultados se utiliza la distribución de frecuencia absoluta y relativa, dispuestos en tablas y gráficos. En conclusión, se presenta la situación de la investigación en innovaciones institucionales participativas en la zona, así como una agenda de investigación para orientar futuras investigaciones sobre el tema.

Palabras clave: Participación social. Innovación institucional. Gestión pública. 


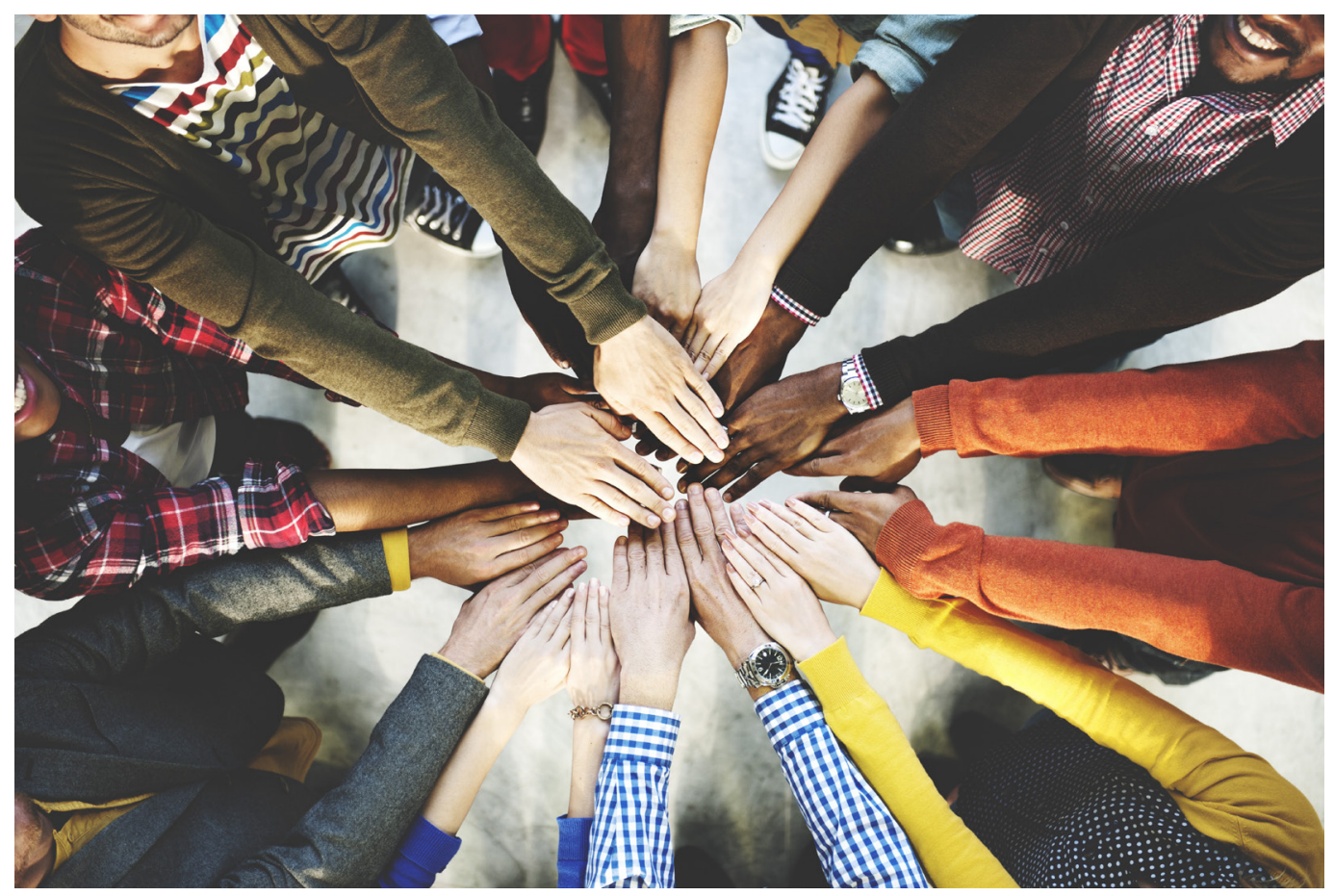

\section{INTRODUÇÃO}

As relações entre o Estado e a sociedade no Brasil têm-se modificado nos últimos anos, pois com o processo de democratização o protagonismo exclusivo do Estado vem sendo posto em questão e isso está possibilitando um maior controle e participação social. A atuação de uma sociedade civil mais organizada, herdeira dos movimentos sociais das décadas de 1960-1980, abriu espaço para a emergência de inovações na gestão pública, no que se refere à participação, do ponto de vista institucional. A Constituição da República Federativa do Brasil, promulgada em 1988, após grande mobilização popular por participação no processo constituinte, incorporou diversas modalidades de participação social nas formas de atuação do Estado, nos três níveis da federação, motivo pelo qual ficou conhecida como a Constituição Cidadã.

Com a nova Constituição, consolidou-se o processo de inovação institucional que já vinha sendo elaborado na sociedade brasileira. Dessa forma, foram valorizadas, na Carta Magna, as possibilidades de exercício da democracia direta, como o plebiscito, o referendo, a iniciativa popular de lei, as audiências públicas e as conferências nacionais, entre outras. A referida Constituição institucionalizou, ainda, os conselhos gestores de políticas públicas, com o objetivo de garantir, em todos os níveis da federação, a participação da sociedade civil na gestão democrática e descentralizada das políticas públicas. A Constituição, dessa maneira, legitima experiências participativas que surgiram durante a década de 1980: conselhos gestores, Orçamento Participativo, fóruns temáticos e conferências nacionais.

Assim, a inscrição de espaços de participação da sociedade no arranjo constitucional da gestão pública brasileira possibilitou a criação de novos formatos institucionais destinados à consolidação dos valores democráticos, da transparência e de possibilidades de efetivo controle social na atuação do Estado, no tocante às políticas públicas. Rocha (2008) sustenta que, dessa

\footnotetext{
* Fonte da imagem: Shutterstock. Disponível em: http://www.shutterstock.com/pt/pic.mhtml?utm_source=44814\&tpl=44814-43068\&utm_ medium=Affiliate\&\&utm_campaign=Pixabay\&irgwc=1\&id=344201303. Acesso em 05 mai. 2016.
} 
forma, a Constituição Federal de 1988 apostou no potencial de "novas institucionalidades" mediante o reconhecimento, em caráter legal e formal, da participação social na gestão pública.

Dessa forma, a partir da Constituição de 1988, no âmbito das relações entre democracia e gestão, um conjunto de inovações institucionais e políticas emergiu, procurando democratizar a gestão pública. Sua importância vem crescendo de tal modo, que essas inovações foram incorporadas como política governamental - a Política Nacional de Participação Social (BRASIL, 2014). Essa política disciplina o funcionamento de conselhos, conferências e mesas de diálogo, além de prever a participação via ambientes virtuais, os quais permitirão que os cidadãos e cidadãs contribuam nos processos de formulação e acompanhamento das políticas públicas desenvolvidas pelo governo. Seus desdobramentos, porém, só poderão ser objeto de avaliações futuras, uma vez que sua proposição é muito recente.

Neste artigo, o objetivo foi fazer um levantamento exploratório da literatura nacional sobre Administração Pública, para verificar as investigações conduzidas pela comunidade de pesquisadores sobre as inovações institucionais de caráter participativo, tendo em vista traçar um panorama dos limites e avanços dessas pesquisas, apontando lacunas e estabelecendo uma agenda de investigação. Para isso, na primeira seção, discutiremos, com base na literatura, as mudanças nas relações Estado e sociedade e, no tópico seguinte, as inovações institucionais de caráter participativo. No terceiro tópico, abordamos a metodologia da pesquisa, que consistiu em uma investigação de caráter qualitativo e quantitativo, para selecionar e classificar artigos sobre inovações institucionais participativas, na Revista de Administração Pública (RAP) nas publicações do período de 1990 a 2014 e nas edições de 2004, 2006, 2008, 2010, 2012 e 2014 do Encontro de Administração Pública e Governança da Associação Nacional de Pós-Graduação em Administração (EnAPG-Anpad). No quarto tópico, analisamos os dados e discutimos os resultados, recorrendo às distribuições de frequência absoluta e relativa, dispostas em tabelas e gráficos. Na conclusão, apresentamos o status das pesquisas sobre inovações institucionais participativas na área, bem como uma agenda de pesquisa para orientar futuras investigações sobre o tema.

\section{MUDANÇAS NAS RELAÇÕES ESTADO E SOCIEDADE}

As manifestações de junho de 2013 representaram um marco da insatisfação da população com a qualidade dos serviços públicos, bem como da demanda social por maior participação na formulação e na gestão de políticas públicas. Essa busca da sociedade por participação não é um fenômeno novo, pois a literatura nacional sobre Administração Pública evidencia que, a partir da década de 1980, com a redemocratização, começou a ocorrer um deslocamento do foco do Estado para a sociedade. Em seu livro Administração Pública no Brasil, Keinert (2000) aponta duas matrizes que caracterizam a relação entre Estado e sociedade, observando uma mudança na configuração do conceito de público:

a) Matriz estadocêntrica: baseada no pensamento pós-liberal do início do século XX, que enfatiza o Estado e sustenta o intervencionismo estatal e a interpenetração com o âmbito privado, de modo que o "público localiza-se no Estado";

b) Matriz sociocêntrica: surge a partir dos anos 1980, em um contexto de mudanças desencadeadas pela globalização e avanços nas tecnologias de informação, no âmbito da crise do Estado (fiscal, de intervenção, de modelo de gestão e de legitimidade), que demarca uma identificação maior com a sociedade, com os direitos de cidadania e com a democracia, realizando uma distinção entre estatal e público, a qual passa a compreender este último conceito de um modo mais amplo que o primeiro.

Segundo Keinert (2000), em um primeiro momento, no período de 1937-1979, o público refere-se ao estatal e as ações eram pensadas do Estado para a sociedade. Com a crise do Estado, esse binômio é questionado, de modo que em um momento posterior o conceito de público ultrapassa os limites do estatal, ampliando-se para incluir múltiplos atores, formas jurídicas e gerenciais. A ampliação do conceito de público

[...] exige novos formatos organizacionais que garantam efetivamente a publicizacão do modus operandi do Estado, das organizações da sociedade civil e, até mesmo, das próprias empresas, já que, como se disse, o público precisa tornar-se um valor compartilhado, mais do que uma localização institucional. Neste sentido, mesmo que, à primeira vista pareça que a administração pública tenha 
perdido sua relevância em função desta ampliação, ocorre exatamente o contrário - torna-se estratégica para preservar o espaço público num contexto institucional bem mais complexo (KEINERT, 2000, p. 92, grifo do autor).

Nesse contexto, Keinert (2000) aponta, ainda, o surgimento de uma rede complexa de organizações, como associações com grau mínimo de institucionalização, as próprias empresas que passam a incluir responsabilidade social em suas estratégias e o setor público não estatal, composto, basicamente pelas Organizações Não Governamentais (ONG), pelas Organizações da Sociedade Civil de Interesse Público (OSCIP) e pelas Organizações Sociais (OS).

No livro Por uma nova Gestão Pública, Paes de Paula (2003) acrescenta que, nesse contexto institucional ampliado, surgiram reinvenções institucionais que visam a atender à demanda por participação social, de modo a validar esse novo conceito de público. A autora identifica um descompasso entre três dimensões que considera fundamentais para a gestão pública democrática: a dimensão econômico-financeira, a dimensão institucional-administrativa e a dimensão sociopolítica.

A dimensão econômico-financeira se relaciona com os problemas no âmbito das finanças públicas e dos investimentos estatais, envolvendo questões de natureza fiscal, tributária e monetária. A dimensão institucional-administrativa abrange os problemas de organização e articulação dos órgãos que compõem o aparato estatal, como as dificuldades de planejamento, direção e controle das ações estatais e a questão da profissionalização dos servidores públicos para o desempenho de suas funções. Já a dimensão sociopolítica compreende problemas situados no âmago das relações entre Estado e sociedade, envolvendo os direitos dos cidadãos e sua participação na gestão pública.

De acordo com Paes de Paula (2003), a vertente gerencial, que embasa a nova Administração Pública, também conhecida como Administração Pública Gerencial, concebida e implementada pelo ex-ministro da Administração e Reforma do Estado, Luiz Carlos Bresser Pereira, durante o governo de Fernando Henrique Cardoso (1994-2002), enfatizou as dimensões econômico-financeira e institucional-administrativa, mas não incorporou amplamente a abordagem da dimensão sociopolítica. Em oposição a esta, herdeira dos movimentos sociais das décadas de 1960, 1970 e 1980, a vertente societal, que busca edificar o que a autora denomina uma Administração Pública Societal, fez tentativas, nos níveis municipal, estadual e federal, de inserir a dimensão sociopolítica em suas experiências de gestão, repensando as instituições e a dinâmica administrativa. Isso deu origem a novos formatos institucionais que incluem a participação social, como os conselhos gestores, o Orçamento Participativo e os fóruns temáticos. Havia expectativas de que o projeto político da vertente societal fosse encampado a partir do governo de Luiz Inácio Lula da Silva, porém os avanços ainda são limitados. Conforme já apontado, as manifestações sociais que eclodiram em junho de 2013 pela melhoria dos serviços públicos talvez também indiquem que a demanda por participação social continua insatisfeita. A presidente Dilma Rousseff procurou responder a essa demanda instituindo por decreto a Política Nacional de Participação Social (BRASIL, 2014), que procura consolidar a participação como um direito social. Entre as instâncias e os mecanismos de participação social, encontram-se: Conselho de Políticas Públicas, Comissão de Políticas Públicas (CPP), Conferências Nacionais, Ouvidoria Pública Federal, Mesas de Diálogo, Fórum Interconselhos, Audiências Públicas, Consultas Públicas e Ambiente Virtual de Participação Social. Foi estabelecido também um Comitê Governamental de Participação Social, cujo funcionamento será disposto pela Secretaria Geral da Presidência da República. Os objetivos da Política Nacional de Participação Social (PNPS) são:

I - consolidar a participação social como método de governo;

II - promover a articulação das instâncias e dos mecanismos de participação social;

III - aprimorar a relação do governo federal com a sociedade civil, respeitando a autonomia das partes;

IV - promover e consolidar a adoção de mecanismos de participação social nas políticas e programas de governo federal;

$V$ - desenvolver mecanismos de participação social nas etapas do ciclo de planejamento e orçamento; $\mathrm{VI}$-incentivar o uso e o desenvolvimento de metodologias que incorporem múltiplas formas de expressão e linguagens de participação social, por meio da internet, com a adoção de tecnologias livres de comunicação e informação, especialmente, softwares e aplicações, tais como códigos fonte livres e auditáveis, ou os disponíveis no Portal do Software Público Brasileiro;

VII - desenvolver mecanismos de participação social acessíveis aos grupos sociais historicamente excluídos e aos vulneráveis; 
VIII - incentivar e promover ações e programas de apoio institucional, formação e qualificação em participação social para agentes públicos e sociedade civil; e IX - incentivar a participação social nos entes federados.

Nesse contexto, novos formatos institucionais como conselhos, Orçamento Participativo, audiências públicas, fóruns e conferências vêm se expandindo, uma vez que um governo democrático, nos dias atuais, não pode mais prescindir dessas instâncias participativas como forma de captar as demandas sociais e discutir com a sociedade os rumos do país. Sua importância cresceu de tal modo que essas inovações foram incorporadas como política governamental, como já citado, bem como na prática cotidiana da gestão pública em todos os níveis da federação.

No entanto, a tentativa de enfeixar as inovações institucionais participativas em uma política pública abrangente já nasceu cercada por controvérsias. Na imprensa nacional, observamos alguns elogios (PARTICIPAÇÃO, 2014; BRESSER-PEREIRA, 2014), mas principalmente críticas e reações conservadoras (CONSTANTINO, 2014), que refletem os tabus que em geral cercam a participação social, uma vez que o Estado tende a ser considerado o único responsável pelas questões públicas. Essas críticas englobam, entre outras coisas, a noção de que a participação social representa uma ameaça ao Poder Legislativo e ao poder político do Estado, uma redução da eficiência governamental e um obstáculo à exclusividade da burocracia estatal, que, em tese, deveria ter o monopólio do conhecimento administrativo. Há ainda quem considere a ampliação da participação social uma conversão ao regime comunista e até mesmo, paradoxalmente, uma ameaça à democracia. De outro lado, da parte dos movimentos sociais emerge a sempre tão temida cooptação pelo Estado. Outros formadores de opinião, que enfatizam o aspecto legal, questionaram se tal iniciativa deveria ser fruto de um decreto presidencial, identificando em tal ato um viés autoritário. A polêmica culminou com o veto do decreto pela Câmara dos Deputados (DECRETO, 2014) e em um manifesto de apoio dos intelectuais que circulou nas redes sociais (MANIFESTO, 2014). O decreto ainda aguarda avaliação pelo Senado, de modo que o desfecho é imprevisível.

Apesar de toda controvérsia em torno do assunto, acreditamos que é possível considerar esses novos formatos institucionais verdadeiras inovações de caráter participativo, mas o que consideramos inovação nesses casos?

\section{INOVAÇÕES INSTITUCIONAIS PARTICIPATIVAS}

Pinho e Santana (1998), ao examinar o objeto inovação na gestão pública, propõem algumas categorias de inovação, das quais destacamos a gestão democrática, que trata a inovação do ponto de vista de uma gestão participativa, comunitária, sem paternalismo e que combate o clientelismo. Spink $(2006$, p. 37) retoma essa discussão mais tarde ao tratar do Programa Gestão Pública e Cidadania, abordando o que seria inovação para os próprios inovadores, ou seja, aqueles que implementaram iniciativas consideradas inéditas. Partindo de suas elaborações, tratamos como inovações institucionais de caráter participativo novos arranjos institucionais que garantam a "inclusão ativa e coletiva, abrangendo participação e cogestão na busca de soluções e no monitoramento de ações" (SPINK, 2006, p. 37).

Na mesma direção, Farah (2006) trata de um eixo de inovações que incide sobre os processos políticos e administrativos, os quais afetam como as políticas públicas são elaboradas. Isso implica saber quais são os atores envolvidos na formulação e na implementação das políticas e como esses atores se relacionam entre si, de modo que se estabeleçam novos processos decisórios e novas formas de gestão, que efetivamente democratizem o policy making ao garantir a participação social. Nesse âmbito, segundo a autora, situam-se os conselhos em áreas como saúde e educação, a participação da sociedade civil na elaboração e no acompanhamento do orçamento público, a ajuda mútua e a cooperação em projetos de habitação e o engajamento de atores sociais nas políticas de desenvolvimento local.

A participação social em tais arranjos institucionais também pode ser compreendida do ponto de vista do conceito de cidadania deliberativa, alicerçado no pensamento de Jürgen Habermas. Segundo Tenório e Marques Filho (2006, p. 109), dessa perspectiva de cidadania as questões públicas

[...] não devem ser planejadas, executadas e avaliadas exclusivamente pelo governo de turno, mas compartilhadas com as diferentes organizações e/ou representações da sociedade civil. Compartilhamento 
que deve ocorrer por meio de ações comunicativas, práticas argumentativas, nas quais o cidadão decide, coletivamente, com poderes constituídos, os interesses da sociedade.

De acordo com Avritzer (2008), as instituições participativas se contrapõem aos formatos tradicionais de instituição política, pois são formas diferenciadas de incorporação de cidadãos e associações da sociedade civil e se caracterizam justamente pela deliberação sobre políticas públicas. Para o autor, há três formas por meio das quais os cidadãos, ou associações da sociedade civil, participam do processo decisório político: a) processo de partilha de poder, que implica a constituição de uma instituição em que atores estatais e da sociedade civil participam, mas que não incorpora um número amplo de atores sociais e é regulado por lei, como é o caso dos conselhos gestores; b) desenho participativo de baixo para cima, com livre entrada dos participantes que elegem delegados e conselheiros, como é o caso do Orçamento Participativo; e c) processo de ratificação pública, em que os atores da sociedade civil não participam do processo decisório, mas são chamados a referendá-los publicamente, como as audiências públicas.

Os conselhos gestores de políticas públicas nasceram na década de 1980 e foram incorporados pela Constituinte de 1988, englobando diversas áreas (por exemplo, Conselho Nacional de Assistência Social (CNAS), Conselho Nacional da Criança e do Adolescente (Conanda), Conselhos de Saúde e Conselho Nacional da Educação (CNE), entre outros). A ideia é antiga, o que é novo é seu caráter deliberativo e sua tentativa de romper com a tradição autoritária da Administração Pública brasileira, além de estabelecer um papel mais ativo da sociedade na formulação e na implementação de políticas públicas. Cada conselho se caracteriza por sua paridade e sua correlação de forças e alianças na definição de um projeto ou política pública.

Para Almeida e Tatagiba (2012), os conselhos já atingiram sua maioridade, pois não são mais apenas "experiências" ou "apostas", uma vez que refletem inegáveis conquistas no que se refere à institucionalidade democrática. Os conselhos caracterizam-se por seu caráter plural e híbrido, uma vez que são compostos por representantes estatais, da sociedade civil e de prestadores de serviços públicos, o que torna o processo decisório mais justo e legítimo, uma vez que contempla diversos interesses na elaboração e na execução de políticas públicas. As autoras citam a Pesquisa de Informações Básicas Municipais, do Instituto Brasileiro de Geografia e Estatística (Munic/IBGE) de 2001, que indicava que 90,00 \% dos munícipios brasileiros abrigavam conselhos nas áreas da saúde, assistência e criança e adolescente, o que representa um número bastante expressivo de conseIhos municipais em atividade. Dados da pesquisa de Bremaeker (2001) para o Instituto Brasileiro de Administração Municipal (Ibam) revelam que em 1999 existiam no Brasil 26.859 conselhos municipais em funcionamento, o que significa uma média de 4,88 conselhos por município. Um levantamento feito por Tatagiba em 2011 identificou um total de 541 conselhos na esfera estadual, em uma média de 20 conselhos por estado. Durante o governo Lula foram criados 16 novos conselhos nacionais, sendo que há mais de 30 deles em atividade hoje. No que se refere às pesquisas acadêmicas, as autoras identificaram 340 dissertações e teses entre 2005 e 2009 sobre o tema, em diversos campos de estudos, o que reflete a relevância do fenômeno.

Os conselhos são contribuições incontestáveis para a gestão democrática, ainda que haja muitos desafios a ser superados para um maior aproveitamento desse tipo de organização. Teixeira (2000) chama a atenção para o risco de corporativismos e a necessidade de uma base ampliada de representação, bem como formas de financiamento e capacitação dos conseIheiros. Além disso, é preciso estar vigilante para evitar assimetrias entre a representação da sociedade civil e a representação estatal, uma vez que isso distancia o conselho das bases populares e facilita a cooptação (RAICHELIS, 2000; BAVA, 2000; TATAGIBA, 2002).

O Orçamento Participativo também teve origem na década de 1980, mais precisamente a partir da experiência do Conselho Popular de Vila Velha (CCVV) em 1985. Em seguida vários governos de frentes populares, compostas pelo Partido dos Trabalhadores (PT) e outros partidos de esquerda, encamparam a experiência, destacando-se o caso de Porto Alegre, que teve início em 1988 e perdura até hoje. Outras experiências surgiram em municípios como Mauá (SP), Ribeirão Pires (SP), Santo André (SP), Distrito Federal (DF), Recife (PE), Belo Horizonte (MG) e São Paulo (SP), entre outros, chegando a atingir 170 municípios (AVRITZER, 2008). Cada experiência de Orçamento Participativo tem sua especificidade e os arranjos institucionais variam, de modo que há dificuldades para compará-los, mas contrapor experiências sempre é útil para captar limites e potencialidades. Carvalho e Felgueiras (2000) conduziram um estudo comparativo dos casos de Mauá, Ribeirão Pires e Santo André, concluindo que fatores como estabilidade, transparência de regras, articulação com outros espaços participativos, participação do conselho popular do município, estabelecimento de critérios de equidade entre regiões e formas de monitoramento da execução orçamentária, têm um efeito positivo no que se refere ao grau de participação. 
Analisando os casos de Orçamento Participativo de Porto Alegre, São Paulo e Belo Horizonte, Avritzer (2008) concluiu que, embora este seja fortemente democratizante, a implementação de políticas participativas depende bastante da vontade política do governante. A cultura política também influencia, pois no caso de Porto Alegre, que se notabiliza pela perpetuidade, há uma forte tradição de organização da sociedade civil, principalmente dos movimentos comunitários a partir de 1950. Já em Belo Horizonte, essa tradição começa a se consolidar a partir da década de 1970, ao passo que em São Paulo isso ocorreu nos anos 1980, com a redemocratização.

As audiências públicas são instrumentos de participação popular amparados pela Constituição de 1988, reguladas por leis federais, Constituições estaduais e leis orgânicas municipais. Nesse espaço, os Poderes Executivo, Legislativo ou Judiciário (Ministério Público (MP)) expõem temas como elaboração de políticas públicas, ou projetos de lei em andamento, para debater com a população, bem como se discutem políticas e leis já implementadas. Trata-se de uma reunião de caráter informal, coordenada pelo órgão competente e entidades da sociedade civil que a demandaram, em que os cidadãos são chamados a se manifestar (PÓLIS, 2005). Muitas delas ocorreram na discussão do Plano Diretor dos municípios (AVRITZER, 2008).

Ainda vale ressaltar as experiências dos fóruns temáticos e das conferências nacionais. De acordo com Paes de Paula (2003), os fóruns temáticos são da mesma época dos conselhos e do Orçamento Participativo e se caracterizam por atuar paralelamente ao poder público e não envolver processo decisório, mas apenas troca e debate de ideias. Os mais conhecidos, e ainda ativos, são o Fórum Nacional de Reforma Urbana (FNRU), o Fórum Nacional da Participação Popular nas Administrações Municipais, o Fórum Intermunicipal da Cultura, o Fórum Nacional da Ação da Cidadania, o Fórum Brasileiro de ONGs e Movimentos Sociais para o Meio Ambiente e Desenvolvimento (FBOMS) e o Fórum Social Mundial (FSM). Eles se caracterizam por ser fluidos e dinâmicos, com períodos de maior ou menor atividade e apesar de seu caráter informal, alguns ganharam muita importância, como o (FNRU) e o FSM.

Já as conferências nacionais, segundo Avritzer (2012), são organizadas pelo governo. A primeira delas data da década de 1940, na Era Vargas, e foram realizadas 115 daí em diante, sendo 74 no governo Lula. Em vinte anos, foram promovidas 80 conferências: 21 na área da saúde, 20 sobre o tema das minorias, 6 sobre meio ambiente, 22 acerca do Estado, economia e desenvolvimento, 17 sobre educação, cultura, assistência social e esportes e 11 sobre direitos humanos. Para o autor, as conferências nacionais foram a principal política participativa do governo federal, sendo que o padrão de participação social no Brasil (6,5\% da população esteve envolvida nesses eventos) é homogêneo, pois há uma continuidade entre a participação no âmbito local e no plano nacional. Além disso, as conferências têm fortes elementos deliberativos e debates de ideias, sendo que nem sempre a posição governamental prevalece. Do ponto de vista da efetividade, ainda há lacunas, pois não há uma forma de gestão que se articule claramente com as decisões das conferências nacionais.

\section{METODOLOGIA}

O objetivo deste artigo foi fazer um levantamento exploratório da literatura nacional sobre participação social na Administração Pública, a fim de traçar um panorama inicial dos limites e avanços das pesquisas sobre inovações institucionais de caráter participativo na comunidade de pesquisadores, de modo a verificar os avanços obtidos, apontar lacunas e compor uma agenda de pesquisa. Para isso, analisamos os artigos publicados na Revista de Administração Pública (RAP) e no Encontro de Administração Pública e Governança da Associação Nacional de Pós-Graduação em Administração (EnAPG-Anpad) de 1990 a 2014.

O corte temporal (1990-2014) abrange todo o período pós-Constituição de 1988, que foi o momento em que essas inovações institucionais se consolidaram. O período em análise é bastante significativo, pois abrange um espaço de tempo considerável, de quase 25 anos, período no qual a participação social consolidou-se no Brasil. A RAP é um dos periódicos mais representativos e mais antigos da área, publicado desde 1967, sem interrupções, pela Escola Brasileira de Administração Pública (Ebap, atualmente, Ebape), da Fundação Getulio Vargas (FGV), representando um dos centros vitais de difusão do conhecimento na área.

Além disso, analisamos também os artigos apresentados no principal encontro acadêmico da área, o Encontro de Administração Pública e Governança da Associação Nacional de Pós-Graduação em Administração (EnAPG-Anpad), que teve sua primeira edição em 2004, ocorrendo sucessivamente a cada dois anos: 2006, 2008, 2010, 2012 e 2014. Esse encontro foi uma iniciativa 
da divisão acadêmica de Administração Pública e Gestão Social da Anpad, delineada no $27^{\circ}$ Congresso da Anpad, que ocorreu em 2003. A inclusão da produção do encontro na análise se justifica não só por sua importância para a comunidade de pesquisadores, mas também porque desde sua primeira edição há uma demanda estimulada de trabalhos sobre participação social na Administração Pública, que sofre modificações ao longo do tempo.

Na edição de 2004 do encontro, a demanda se estabelece no tema 6, Direitos sociais, participação e movimentos sociais. Em 2006, o tema 6 prossegue, mas com outro nome: Sociedade civil e cidadania: novas formas de organização, demandas e movimentos sociais. Em 2008, a demanda é estimulada pelo tema 8, Sociedade civil e cidadania: novas formas de organização e novos movimentos sociais. Em 2010, o tema não aparece e, em 2012, ele é incorporado pelo tema 1, Estado, Sociedade, Governo e Administração Pública. Na edição de 2014, a demanda volta a ter destaque no tema 2, Relações entre Estado e Sociedade.

Para selecionar qualitativamente os artigos, adotamos como critério, com base no que foi constatado na literatura, as seguintes inovações institucionais participativas: participação social (de forma ampla), Orçamento Participativo, conselhos, fóruns, conferências, audiências públicas e políticas públicas participativas setoriais (saúde, educação, habitação, meio ambiente e desenvolvimento local, entre outras). Na RAP foram consultados 1.476 artigos e selecionados 55 deles; no EnAPG, 867 artigos foram levantados e 52 identificados de acordo com os critérios. Consolidando os dados, temos 2.345 artigos dos quais 107 foram selecionados. Em tais artigos, foram analisados: o ano de publicação, a inovação institucional objeto da investigação, a metodologia de pesquisa usada (teórico ou teórico-empírico), a autoria e as instituições às quais pertencem os autores. Depois da seleção qualitativa, fizemos uma abordagem quantitativa, usando estatística simples, ou seja, calculamos as frequências absolutas e relativas, bem como elaboramos algumas tabelas e gráficos para obter referências visuais. Em seguida, analisamos os dados e discutimos os resultados.

\section{ANÁLISE DE DADOS E DISCUSSÃo}

Do ponto de vista da representatividade das inovações institucionais participativas no contexto das pesquisas nacionais feitas na área, constatamos que, considerando a importância na prática político-social que o tema ganhou ao longo do tempo, a contribuição teórico-analítica ainda é bem modesta. Os artigos selecionados, 55 publicados pela RAP e 52 publicados pelo EnAPG, em um universo, respectivamente, de 1.476 e 867 artigos, totalizando 2.345 artigos consultados, indicam 3,73\% da produção da RAP e 6,00\% da produção do EnAPG, sendo 4,56\% da produção total nesses dois espaços. É possível especular que a produção maior no EnAPG se deve à demanda estimulada pela presença do tema nas chamadas do encontro, que garantem um espaço para esse tipo de produção.

Analisando a distribuição da produção ao longo do tempo, no caso da $R A P$, a cada década temos os seguintes números:

Tabela 1

Distribuição temporal dos artigos selecionados - RAP

\begin{tabular}{|c|c|c|}
\hline Década & Fa & Fr (\%) \\
\hline 1990 & 17 & 30,91 \\
\hline 2000 & 19 & 34,55 \\
\hline 2010 & 19 & 34,55 \\
\hline Total & $\mathbf{5 5}$ & $\mathbf{1 0 0}$ \\
\hline
\end{tabular}

Fonte: Elaborada pelas autoras. 


\section{Gráfico 1}

Artigos sobre inovações institucionais participativas publicados pela $R A P$ - percentual por década

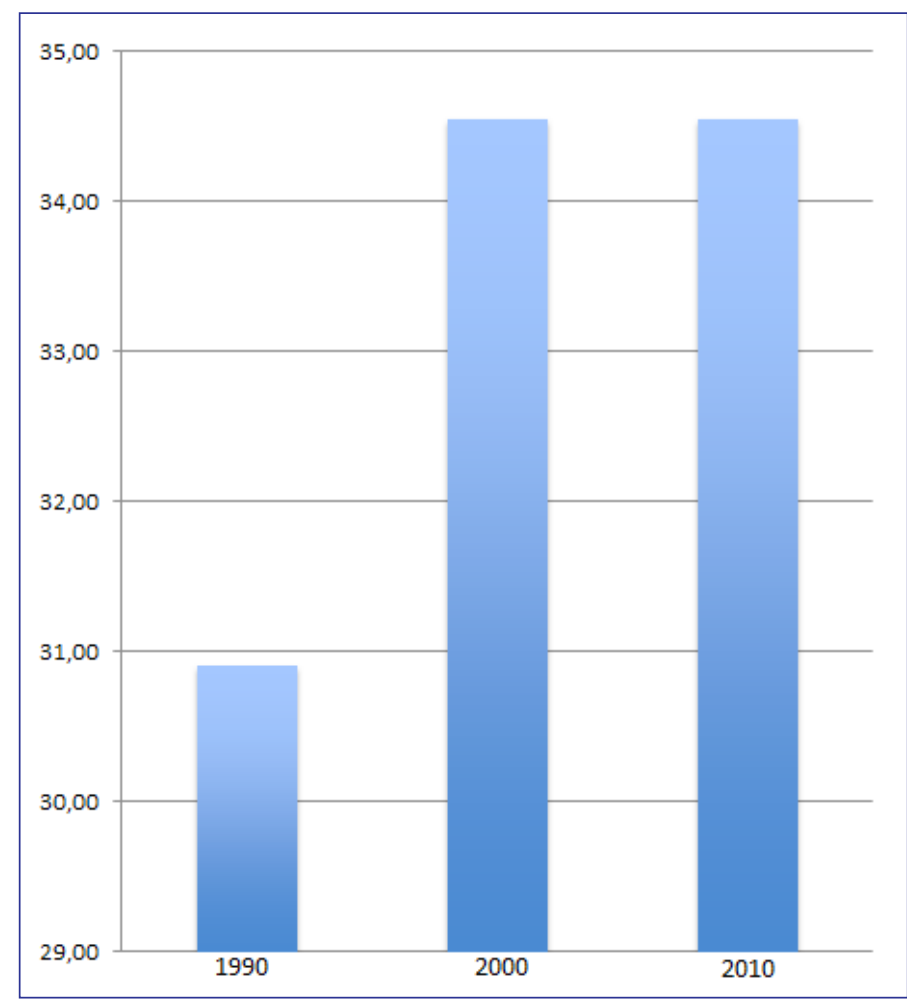

Fonte: Elaborado pelas autoras.

Os números mostram uma evolução crescente, especialmente se considerarmos que a década 2010 se encontra na metade e já temos $34,55 \%$ de artigos publicados, o mesmo montante de toda a década anterior.

Já na análise da distribuição da produção ao longo do tempo para o EnAPG, a cada edição do encontro temos os seguintes resultados:

Tabela 2

Distribuição temporal dos artigos selecionados - EnAPG

\begin{tabular}{|c|c|c|}
\hline Década & Fa & Fr (\%) \\
\hline 2004 & 6 & 11,54 \\
\hline 2006 & 12 & 23,08 \\
\hline 2008 & 13 & 25,00 \\
\hline 2010 & 8 & 15,38 \\
\hline 2012 & 5 & 9,62 \\
\hline 2014 & 8 & 15,38 \\
\hline Total & $\mathbf{5 2}$ & $\mathbf{1 0 0}$ \\
\hline
\end{tabular}

Fonte: Elaborada pelas autoras. 


\section{Gráfico 2}

\section{Artigos sobre inovações institucionais participativas publicados no Encontro de Administração Pública da ANPAD (EnAPG) - percentual a cada biênio}

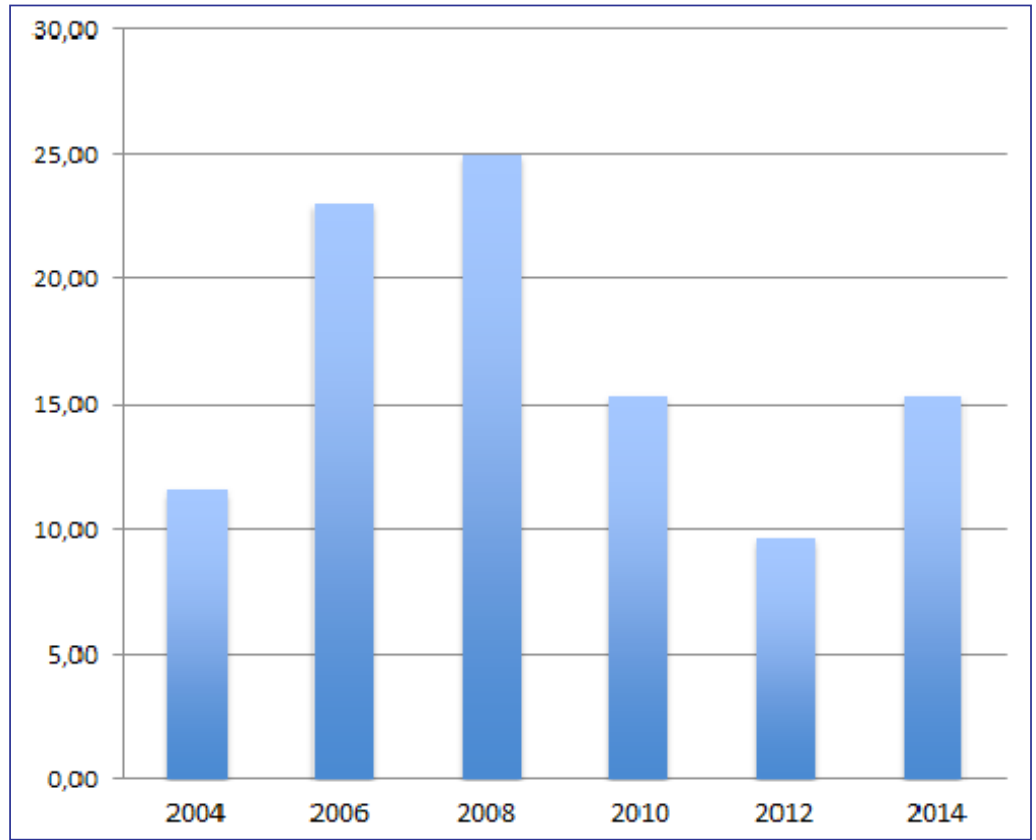

Fonte: Elaborado pelas autoras.

Os resultados evidenciam um crescimento ao longo da década 2000, assim como ocorre no caso da $R A P$, mas com uma retração a partir de 2010, o que talvez se justifique pelo fato de o tema que proporcionava a demanda estimulada ter sido excluído nessa edição e incorporado a outro tema na edição de 2012. A volta ao tema em 2014 teve resultado modesto, mas positivo, pois a produção retomou seu crescimento, alcançando novamente o mesmo patamar de 2010. Essa evidência sugere a importância da demanda estimulada por temas para o desenvolvimento de linhas e agendas de pesquisa.

No que se refere à distribuição das inovações institucionais participativas entre os artigos selecionados, a consolidação dos resultados da RAP e do EnAPG indica o seguinte resultado:

Tabela 3

Distribuição das inovações institucionais participativas - RAP e EnAPG

\begin{tabular}{|l|c|r|}
\hline \multicolumn{1}{|c|}{ Inovação institucional } & Fa & \multicolumn{1}{c|}{ Fr (\%) } \\
\hline Participação social & 43 & 40,19 \\
\hline Políticas públicas setoriais & 35 & 32,71 \\
\hline Conselhos gestores & 15 & 14,02 \\
\hline Orçamento participativo & 9 & 8,41 \\
\hline Audiências públicas & 5 & 4,67 \\
\hline Total & $\mathbf{1 0 7}$ & $\mathbf{1 0 0}$ \\
\hline
\end{tabular}

Fonte: Elaborada pelas autoras. 


\section{Gráfico 3}

\section{Inovações institucionais participativas - RAP e EnAPG}

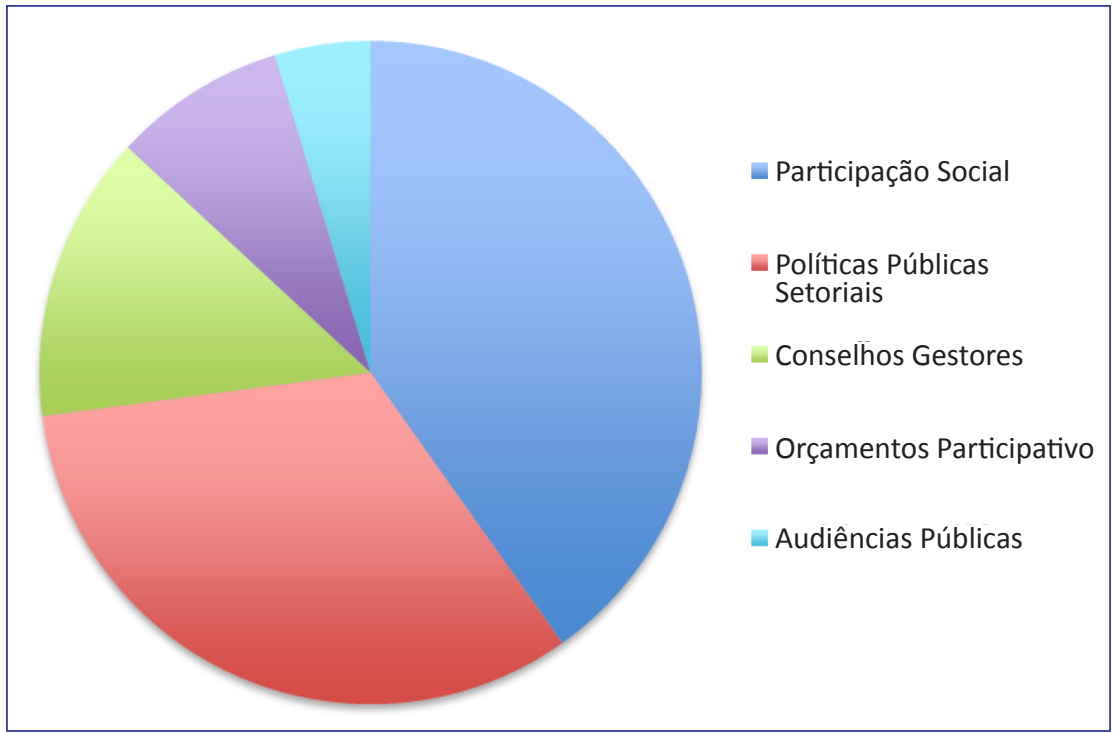

Fonte: Elaborado pelas autoras.

Nessa distribuição, destacam-se a Participação Social e as Políticas Públicas Participativas Setoriais. Digna de nota é a baixa frequência de pesquisas que enfocam os conselhos gestores, o Orçamento Participativo e as audiências públicas, assim como a ausência de pesquisas sobre fóruns e conferências, especialmente considerando o maior grau de inovação institucional dessas iniciativas.

A ênfase na Participação Social, considerada de maneira ampla, bem como nas Políticas Públicas Participativas Setoriais, sugere que o tema inovação institucional participativa tem sido tratado de forma difusa, pois, no primeiro caso, destaca-se a participação como fenômeno novo no âmbito da Administração Pública, sem privilegiar sua institucionalização e, no segundo, aborda-se a participação partindo das políticas públicas, o que enfatiza o protagonismo do Estado nessas iniciativas, na qualidade de promotor delas, e não das inovações institucionais criadas por demandas sociais.

Examinando a distribuição das Políticas Públicas Participativas Setoriais, percebemos um destaque para as Políticas Públicas de Desenvolvimento Local, Meio Ambiente e Saúde.

\section{Tabela 4}

\section{Distribuição das Políticas Públicas Participativas Setoriais - RAP e EnAPG}

\begin{tabular}{|l|c|c|}
\hline \multicolumn{1}{|c|}{ Políticas públicas } & Fa & Fr (\%) \\
\hline Desenvolvimento local & 13 & 37,14 \\
\hline Meio ambiente & 9 & 25,71 \\
\hline Saúde & 7 & 20,00 \\
\hline Habitação & 5 & 14,29 \\
\hline Educação & 1 & 2,86 \\
\hline Total & 35 & 100 \\
\hline
\end{tabular}

Fonte: Elaborada pelas autoras. 


\section{Gráfico 4}

Políticas Públicas Participativas Setoriais - RAP e EnAPG

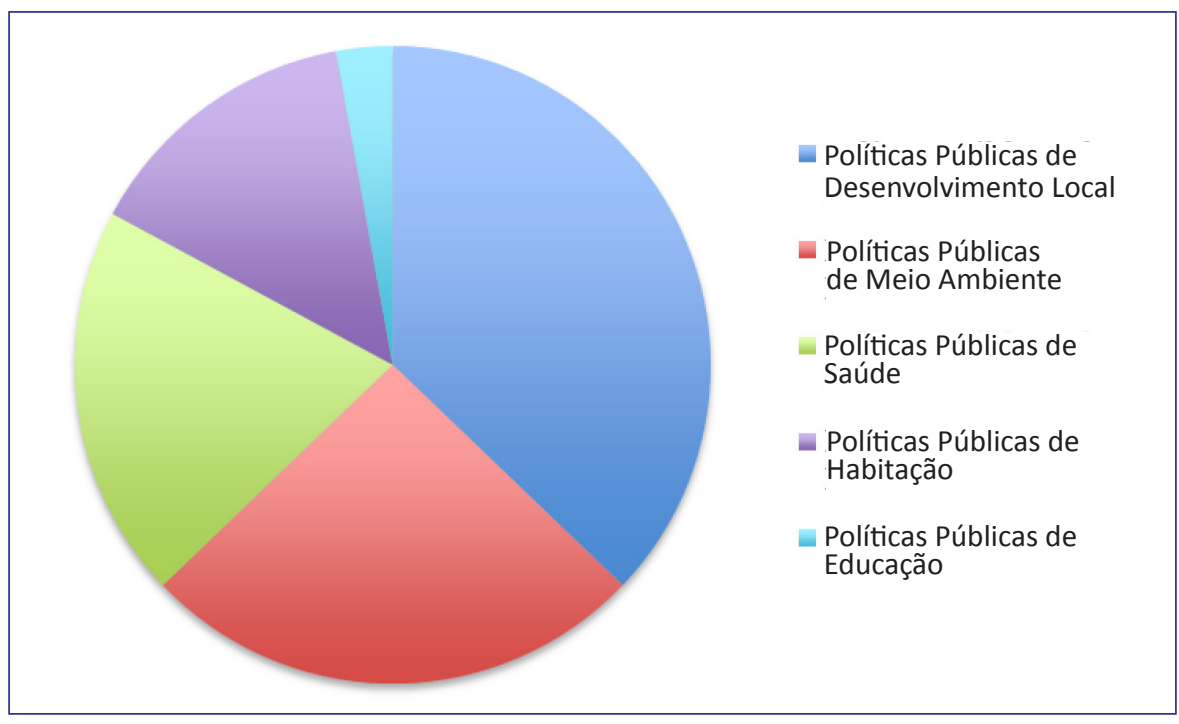

Fonte: Elaborado pelas autoras.

A ênfase em Políticas Públicas de Desenvolvimento Local e Meio Ambiente possivelmente reflete os esforços dos governos municipais em estimular a participação social no planejamento governamental, na geração de renda e na condução do Plano Diretor dos municípios. Em contrapartida, com exceção das Políticas Públicas de Saúde, fica evidente a pequena ênfase das pesquisas em políticas sociais como educação, habitação, assistência social, transporte e atendimento às minorias, entre outras, ou seja, principalmente aquelas que envolvem prestação de serviços públicos, que foram objeto de demanda nas mobilizações sociais recentes. A exceção é o caso da saúde, que se destacou entre as demais, o que possivelmente é reflexo de elevado grau de organização da sociedade civil quanto a essa política social, uma vez que a evolução do movimento sanitarista e a consolidação do Sistema Único de Saúde (SUS) ocorreu com protagonismo da sociedade civil organizada.

Os números consolidados ainda demonstram um predomínio de pesquisas de natureza empírica e teórico-empírica, com destaque para os estudos de caso, pois do total de 107 artigos selecionados, apenas 13 apresentam abordagem teórica, ou seja, 12,15\%, número que talvez não surpreenda quando consideramos que estamos tratando de um fenômeno de natureza aplicada. No entanto, podemos especular que há uma deficiência no que se refere às abordagens teóricas e a uma baixa capacidade de se fazer análises epistemológicas, o que é consistente com a atual crise dos referenciais que guiam as ciências sociais, além de denotar uma tendência de instrumentalização dos estudos em detrimento de análises de caráter conceitual. Dessa forma, é possível que maior ênfase em análises teóricas pudesse enriquecer o debate futuro.

Em contraposição, a análise das autorias e das instituições de origem dos autores não resultou em dados conclusivos, pois a heterogeneidade é muito grande: a baixa frequência de trabalhos por autor sugere que ainda não há maior persistência dos investigadores nessa linha de pesquisa. Esse fenômeno da descontinuidade também não é novo, pois, inclusive, já foi constatado em outras áreas da administração na academia brasileira. Entre os autores, destaca-se a produção dos professores Fernando Guilherme Tenório da Ebape-FGV, com 4 artigos, e Marta Ferreira Santos Farah da Escola de Administração de Empresas de São Paulo (AESP-FGV), com 3 artigos.

As evidências obtidas nos levam a questionar o que motivou a pouca atenção dada pelos pesquisadores às inovações institucionais participativas, em especial conselhos gestores, Orçamento Participativo, fóruns, conferências e audiências públicas. Seria o reduzido espaço concedido pelo Estado à participação social no campo das políticas sociais, que não produz fenômenos para ser estudados? A consulta à literatura e às pesquisas feitas, no entanto, sugerem que tais fenômenos já ocorrem em número expressivo em nossa sociedade, de modo que esses parecem ser, de fato, objetos empíricos ainda pouco explorados pelos pesquisadores. 


\section{CONSIDERAÇÕES FINAIS}

A participação social ganhou grande importância nas últimas décadas no Brasil. Seu ponto de partida foram iniciativas de caráter participativo no âmbito da gestão pública ainda na década de 1980. Essas foram incorporadas e institucionalizadas pela Constituição de 1988 e o processo de ampliação da participação foi crescente, culminando nas recentes manifestações populares, que criticam a gestão pública atual e a qualidade dos serviços públicos, mas também demandam maior protagonismo da sociedade civil nas decisões de interesse social.

O objetivo deste artigo foi fazer uma análise exploratória das pesquisas nacionais sobre inovações institucionais participativas na área de Administração Pública, abordando a RAP e o EnAPG, para apontar seus limites e avanços, bem como compor uma agenda de investigação. Os dados apresentados e analisados demonstram que o status das pesquisas sobre o tema sugere um crescimento de sua importância, porém ainda com reduzida repercussão e consolidação em nosso meio acadêmico, pois há numerosos fenômenos de participação na Administração Pública se reproduzindo em nossa sociedade que ainda não se tornaram objetos privilegiados de pesquisa. Isso se revela, em primeiro lugar, pela baixa incidência de artigos sobre inovações institucionais participativas tomadas em conjunto no contexto da produção analisada. Além disso, a heterogeneidade de autores e instituições sugere que falta continuidade às investigações e solidez nas linhas de pesquisa, especialmente porque a produção de natureza empírica ainda não permite generalizações, uma vez que há predomínio de estudos de caso. Por outro lado, há uma ausência de balanços abrangentes sobre pesquisas feitas na área e em outros domínios do conhecimento, como a ciência política, que se tem dedicado a esse tema nos últimos anos.

Tal constatação nos leva a questionar se os encontros acadêmicos com demanda estimulada por esses temas, como é o caso do EnAPG, têm sido suficientes para fomentar e consolidar redes e linhas de pesquisa sobre inovações institucionais participativas. Embora outros encontros e periódicos relevantes não tenham sido consultados, nas fontes pesquisadas a fragmentação e a descontinuidade da produção sugerem que os trabalhos costumam ser preparados para apresentação no congresso e posterior publicação em periódicos, mas ainda não é possível constatar maior persistência dos investigadores nessa linha de pesquisa, uma vez que, pelo menos neste levantamento, não se identificam trabalhos posteriores que demonstrem uma evolução das pesquisas no sentido de gerar continuidade e cumulatividade.

Em segundo lugar, embora fenômenos como conselhos gestores, Orçamento Participativo, audiências públicas, fóruns e conferências, que são instituições participativas que afetam a Administração Pública estejam se estabelecendo em números expressivos no cotidiano dos governos, esses receberam pouca ou nenhuma atenção dos pesquisadores. A Participação Social e as Políticas Públicas Participativas Setoriais se destacam na produção, o que é um avanço, mas falta à questão da participação social lato sensu tratamento teórico mais sistematizado. No campo das políticas setoriais, a questão da participação nas políticas sociais merece mais investigação, especialmente se consideramos a consolidação de conselhos gestores na área da educação, da assistência social, da saúde e da criança e do adolescente. A ausência de pesquisas sobre fóruns e conferências se notabiliza, pois essas experiências vêm ocorrendo há décadas e alguns espaços participativos estão amplamente consolidados. Por outro lado, o foco na ideia de participação social lato sensu e nas políticas setoriais, em detrimento de inovações participativas institucionais stricto sensu, sugere uma tendência de se estudar os fenômenos da perspectiva do Estado, uma vez que este é o responsável direto pelas políticas públicas e pela concessão de oportunidades de participação. Tais evidências nos permitem especular que, embora nas relações entre Estado e sociedade tenha ocorrido um deslocamento da matriz estadocêntrica para a matriz sociocêntrica, colocando a Administração Pública Societal no centro da pauta pública, no que se refere às pesquisas parece ainda haver uma permanência no registro estadocêntrico, pois o olhar nas investigações se sustenta na direção do Estado para a sociedade, evitando o protagonismo social, ou seja, um redirecionamento desse olhar a partir da sociedade. Considerando a reduzida produção e o foco no eixo estatal, vale a pena questionar se os tabus que cercam a participação social estão obliterando as pesquisas sobre o tema. Considerando esse status sobre a pesquisa sobre inovações institucionais participativas na Administração Pública, que inclui seus avanços e limites, sugerimos a seguinte agenda de pesquisa:

1) Participação social: sistematização teórica sobre a produção na Administração Pública e em outros domínios conexos de pesquisa, como é o caso da ciência política, do urbanismo, do meio ambiente, da educação e da saúde, entre outros; 
2) Políticas públicas participativas setoriais: balanço da produção na área sobre saúde, desenvolvimento local e meio ambiente para constatar avanços, bem como apontar novos caminhos e a necessidade de ampliação de pesquisas empíricas sobre inovações institucionais participativas no campo de políticas sociais, como saúde, educação, moradia, transporte e mobilidade, assistência social e minorias, entre outros;

3) Conselhos gestores e orçamento participativo: levantamento quantitativo das experiências existentes nos níveis municipal, estadual e federal tendo em vista a ampliação de balanços feitos em outras áreas do conhecimento, bem como condução de estudos de casos múltiplos de natureza qualitativa, visando às abordagens comparativas que permitam alcançar resultados transversais, dada a importância e a consolidação dessas iniciativas;

4) Audiências públicas: ampliação das pesquisas feitas, tanto do ponto de vista quantitativo quanto qualitativo, que destaquem a importância do Estado consultar a sociedade em assuntos de interesse coletivo;

5) Fóruns temáticos e conferências: inclusão dessas experiências na pauta de pesquisas a fim de que sejam feitos levantamentos quantitativos e abordagens qualitativas, considerando que a antiguidade e a consolidação dessas justifica que sejam objetos empíricos privilegiados.

Encerrando, vale ressaltar que nossas críticas não visam a reduzir o mérito das pesquisas feitas, apenas apontar lacunas e limites tendo em vista a evolução daquelas. Reconhecemos também as restrições de nossa própria empreitada, pois não foram incluídos outros periódicos e encontros, ainda que a ênfase na RAP e no EnAPG se justifique pelo foco, dimensão e importância desses na área. Além disso, não foi possível, no escopo deste trabalho, fazer uma abordagem qualitativa do conteúdo dos artigos selecionados, a fim de se fazer uma avaliação mais precisa dos avanços, limite esse que pretendemos superar em futuras pesquisas. 


\section{REFERÊNCIAS}

ALMEIDA, C.; TATAGIBA, L. Os conselhos gestores sob o crivo da política: balanços e perspectivas. Serviço Social \& Sociedade, $n$. 109, p. 68-92, 2012.

AVRITZER, L. Instituições participativas e desenho institucional: algumas considerações sobre a variação da participação no Brasil democrático. Opinião Pública, v. 14, n. 1, p. 43-64, 2008.

AVRITZER, L. Conferências nacionais: ampliando e redefinindo os padrões de participação social no Brasil. Texto para Discussão IPEA, n. 1739, p. 1-24, 2012.

BAVA, S. C. Os conselhos como instrumentos da sociedade civil. In: CARVALHO, M. C.; TEIXEIRA, A. C. Conselhos gestores de políticas públicas. Pólis, n. 37, p. 68-69, 2000.

BRASIL. Decreto n. 8.243, de 23 de maio de 2014. 2014. Política Nacional de Participação Social. Disponível em: <http://www.planalto.gov.br/ccivil_03/_Ato2011-2014/2014/Decreto/D8243.htm>. Acesso em: 2 jun. 2014.

BREMAEKER, F. E. J. Os conselhos municipais existentes no Brasil. Estudos Especiais IBAM, v. 23, p. 1-14, 2001.

BRESSER-PEREIRA, L. C. Democracia participativa. 2014. Disponível em: <http://www1.folha.uol.com.br/opiniao/2014/06/1468885-luiz-carlos-bresser-pereira-democracia-participativa.shtml>. Acesso em: 10 jul. 2014.

CARVALHO, M. C.; FELGUEIRAS, D. Orçamento participativo no ABC. Pólis, n. 34, 2000.

CONSTANTINO, R. PT quer amordaçar sociedade civil. 2014. Disponível em: <http://veja.abril.com.br/blog/rodrigo-constantino/tags/ decreto-8-243/>. Acesso em: 3 jul. 2014.

DECRETO sobre conselhos fere a lei e a separação de poderes, diz Alves. 2014. Disponível em: <http://g1.globo.com/politica/noticia/2014/07/decreto-sobre-conselhos-fere-lei-e-separacao-de-poderes-diz-alves.html>. Acesso em: 3 jul. 2014.

FARAH, M. F. S. Inovação e governo local no Brasil contemporâneo. In: JACOBI, P.; PINHO, J. A. Inovação no campo da Gestão Pública local. Novos desafios, novos patamares. Rio de Janeiro: Ed. FGV, 2006. 41-76 p.

KEINERT, T. M. M. Administração Pública no Brasil. Crise e mudanças de paradigmas. São Paulo: Annablume/Fapesp, 2000.
MANIFESTO reúne artistas e intelectuais em apoio à participação social no governo. 2014.

Disponível em: <http://correiodobrasil.com.br/noticias/brasil/manifesto-reune-artistas-e-intelectuais-em-apoio-a-participacao-social-no-governo/711920/>. Acesso em: 3 jul. 2014.

PAES DE PAULA, A. P. Por uma nova Gestão Pública. Limites e potencialidades da experiência contemporânea. Rio de Janeiro: Ed. FGV, 2003.

PARTICIPAÇÃO popular: entenda o novo (e controverso) decreto. 2014. Disponível em: <http://www.cartacapital.com.br/sociedade/ faq-decreto-3508.html>. Acesso em: 3 jul. 2014

PINHO, J. A. G.; SANTANA, M. W. Inovação na Gestão Pública no Brasil: uma aproximação teórico-conceitual. 1998. Disponível em: <http:// www.ufrgs.br/nutep/projetos/AP35.html>. Acesso em: 14 dez. 2015.

PÓLIS. Audiências públicas. Repente, n. 24, 2005.

RAICHELIS, R. Os conselhos de gestão no contexto internacional. In: CARVALHO, M. C.; TEIXEIRA, A. C. Conselhos gestores de políticas públicas. Pólis, n. 37, p. 41-47, 2000.

ROCHA, E. A Constituição Cidadã e a institucionalização dos espaços de participação social: avanços e desafios. 2008. Disponível em: <http://www.ipea.gov.br/participacao/images/pdfs/participacao/ outras_pesquisas/a\%20constituio\%20cidad\%20e\%20a\%20institucionalizao\%20dos\%20espaos\%20de\%20participao\%20social.pdf>. Acesso em: 5 jul. 2014

SPINK, P. A inovação na perspectiva dos inovadores. In: JACOBI, P.; PINHO, J. A. Inovação no campo da Gestão Pública local. Novos desafios, novos patamares. Rio de Janeiro: Ed. FGV, 2006. 23-40 p.

TATAGIBA, L. Os conselhos gestores e a democratização das políticas públicas no Brasil. In: DAGNINO, E. Sociedade civil e espaços públicos no Brasil. São Paulo: Paz e Terra, 2002. 47-106 p.

TEIXEIRA, E. C. Efetividade e eficácia dos conselhos. In: CARVALHO, M. C.; TEIXEIRA, A. C. Conselhos gestores de políticas públicas. Pólis, n. 37, p. 92-96, 2000.

TENÓRIO, F. G.; MARQUES FILHO, H. Cidadania deliberativa: um estudo de caso. In: JACOBI, P.; PINHO, J. A. Inovação no campo da Gestão Pública local. Novos desafios, novos patamares. Rio de Janeiro: Ed. FGV, 2006. 97-116 p.

Ana Paula Paes de Paula

Doutora em Ciências Sociais pelo Instituto de Filosofia e Ciências Humanas; Professora Titular da FACE-UFMG. E-mail: appaula@face.ufmg.br

Tânia Margarete Mezzomo Keinert

Doutora em Administração pela EAESP-FGV; Pesquisadora Científica IV do Instituto de Saúde. E-mail: tania.keinert@uol.com.br 